\title{
The Tpr protein regulates export of mRNAs with retained introns that traffic through the Nxf1 pathway
}

\author{
JOHN H. COYLE, ${ }^{1,2}$ YEOU-CHERNG BOR, ${ }^{1}$ DAVID REKOSH, and MARIE-LOUISE HAMMARSKJOLD ${ }^{3}$ \\ Myles H. Thaler Center for AIDS and Human Retrovirus Research and Department of Microbiology, University of Virginia, Charlottesville, \\ Virginia 22908, USA
}

\begin{abstract}
Post-transcriptional regulation of mRNA includes restriction mechanisms to prevent export and expression of mRNAs that are incompletely spliced. Here we present evidence that the mammalian protein Tpr is involved in this restriction. To study the role of Tpr in export of mRNA with retained introns, we used reporters in which the mRNA was exported either via the Nxf1/Nxt1 pathway using a CTE or via the Crm1 pathway using Rev/RRE. Our data show that even modest knockdown of Tpr using RNAi leads to a significant increase in export and translation from the mRNA containing the CTE. In contrast, Tpr perturbation has no effect on export of mRNA containing the RRE, either in the absence or presence of Rev. Also, no effects were observed on export of a completely spliced mRNA. Taken together, our results indicate that Tpr plays an important role in quality control of mRNA trafficked on the Nxf1 pathway.
\end{abstract}

Keywords: mRNA export; intron retention; nuclear pore; CTE; Nxf1; Tpr

\section{INTRODUCTION}

The mammalian Tpr protein associates with nuclear pore complexes (NPCs) and may constitute an important structural part of the nuclear basket (Cordes et al. 1997; Krull et al. 2004). In addition, this protein has also been found in apparently discrete foci throughout the nuclear interior (Frosst et al. 2002). Although the exact functions of Tpr remain unclear, it has been proposed to serve in regulation of export of $\mathrm{mRNAs}$ into the cytoplasm, possibly as a cellular mechanism for preventing the expression of aberrantly unspliced or mis-spliced isoforms (Fasken and Corbett 2009). Evidence for such a "gatekeeping" function has been established in the case of the Tpr yeast ortholog Mlp1 (Galy et al. 2004; Vinciguerra et al. 2005). In addition, a recent article has reported that Mlp1 interacts genetically with Mex67, the yeast ortholog of the mammalian mRNA export protein Tap/Nxfl (Nxf1), in regulating export of mRNA during heat shock (Carmody et al. 2010).

In spite of the clear role for Mlp1 in mRNA regulation in yeast, no strong evidence has been presented for such a role

\footnotetext{
${ }^{1}$ These authors contributed equally to this work.

${ }^{2}$ Present address: PRA International, 4105 Lewis \& Clark Drive, Charlottesville, VA 22911, USA.

${ }^{3}$ Corresponding author.

E-mail mh7g@virginia.edu.

Article published online ahead of print. Article and publication date are at http://www.rnajournal.org/cgi/doi/10.1261/rna.2616111.
}

for Tpr in mammalian cells. However, Tpr has previously been reported to be involved in regulating Crm1-mediated protein export (Frosst et al. 2002). Since Crm1 is also used to export unspliced and incompletely spliced HIV mRNAs (as well as some other viral RNAs) (Hammarskjöld 1997), this raises the possibility that Tpr may regulate this RNA export as well. However, only a few mammalian cellular mRNAs appear to be exported through the Crm1 pathway (Culjkovic et al. 2006; Prechtel et al. 2006; Schutz et al. 2006). Instead, the Nxf1 protein, in conjunction with another cellular protein, Nxt1, is believed to serve as the major mRNA export receptor (for review, see Erkmann and Kutay 2004).

Many studies support the notion that mammalian cells possess a checkpoint that will normally only allow for the export of mRNA once splicing has been completed (Legrain et al. 1988; Chang and Sharp 1989). Yet, some cellular genes and many viruses express alternatively spliced mRNA isoforms in which one or more introns are retained (Hammarskjöld 1997; Galante et al. 2004; Li et al. 2006). Although some of these are subject to degradation in the cytoplasm through nonsense-mediated decay (NMD) (Green et al. 2003b), there are an increasing number of examples of cellular mRNAs with retained introns, which avoid the NMD machinery and express functional proteins (Forrest et al. 2004; Li et al. 2006; Marinescu et al. 2007; Torrado et al. 2009; Mollet et al. 2010). Retroviruses have become models for this and provide important tools for the analysis of such cellular restriction mechanisms and 
how these mechanisms can be overcome (Hammarskjöld 1997).

All retroviruses must efficiently export and express unspliced mRNA with one or more retained introns, since this RNA constitutes the viral genome and, in addition, is translated into the viral Gag and GagPol proteins (Hammarskjöld 1997). We and others showed many years ago that, in the case of HIV, the action of a specific regulatory protein, Rev, is needed for this process (Hadzopoulou-Cladaras et al. 1989; Hammarskjöld et al. 1989; Malim et al. 1989). Rev interacts directly with a cisacting element in viral mRNA, the Rev Response Element (RRE), to allow efficient export and expression of the HIV mRNAs with retained introns. Rev also interacts directly with Crm1 (Fornerod et al. 1997; Otero et al. 1998), and thus, as a consequence, these mRNAs are exported through this pathway. However, the simpler retroviruses do not express viral regulatory proteins. Instead, many of them use cis-acting constitutive transport elements (CTEs) to export their intronretaining RNAs (Bray et al. 1994; Zolotukhin et al. 1994; Ogert and Beemon 1995). This was first demonstrated by us in the case of Mason Pfizer Monkey Virus (MPMV) (Bray et al. 1994), and these CTEs interact directly with the cellular machinery. It has been shown that the MPMV CTE works through direct interactions with the Nxf1/Nxt1 complex, enabling mRNA export through the Nxf1/Nxt1 pathway (Grüter et al. 1998; Guzik et al. 2001). More recently, we have also shown that the MPMV CTE is probably not of viral origin, since a nearly homologous sequence is found in intron 10 of the NXF1 gene itself ( $\mathrm{Li}$ et al. 2006). This CTE allows the export and expression, through the Nxf1/Nxt1 pathway, of an Nxf1 mRNA that retains intron 10.

The results of the experiments discussed above provide considerable evidence for the notion that there is an intricate regulation of the export of cellular mRNAs, which includes proofreading at the nuclear level to determine whether any introns are remaining. Based on the data from the yeast studies, we have hypothesized that this regulation may involve Tpr.

To further this hypothesis, we decided to investigate the role of $\mathrm{Tpr}$ in the export and expression of mRNA with retained introns using either the Crm1 or Nxf1/Nxt1 pathway. Here we show that perturbation of Tpr through siRNA-mediated knockdown leads to increased export and expression of HIV RNAs with retained introns. However, this effect is only seen when these RNAs are trafficked through the Nxf1/Nxt1 pathway through the use of a CTE. In contrast, no effects were observed when export was mediated by the Crm1/Rev/RRE pathway.

\section{RESULTS}

\section{Knockdown of Tpr increases protein expression from a CTE-containing reporter plasmid}

To modulate Tpr levels, we constructed a plasmid that uses an H1 RNA Pol III promoter to express short hairpin RNA
(shRNA) targeted against the mRNA encoding the endogenous Tpr protein (nucleotides 1376 to 1394 in TPR Accession \#U69668), since it is well established that when shRNA is expressed in cells, it gets cleaved by Dicer to generate siRNA (Brummelkamp et al. 2002). This construct was first tested by cotransfecting cells with a plasmid expressing an eGFP-tagged version of Tpr and examining GFP expression by flow cytometry and microscopy. Both methods indicated that expression from the shRNA plasmid was able to efficiently generate siRNA that targeted Tpr (data not shown).

We next analyzed whether knockdown of endogenous Tpr would have an effect on CTE or Rev/RRE-dependent expression of intron-containing RNA. This was done by cotransfecting the H1-Tpr shRNA plasmid together with reporter plasmids that express the HIV GagPol proteins. As can be seen in Figure $1 \mathrm{~B}$, this resulted in a $>50 \%$ reduction in levels of endogenous Tpr. We have used the GagPol reporter system in multiple previous studies where we have

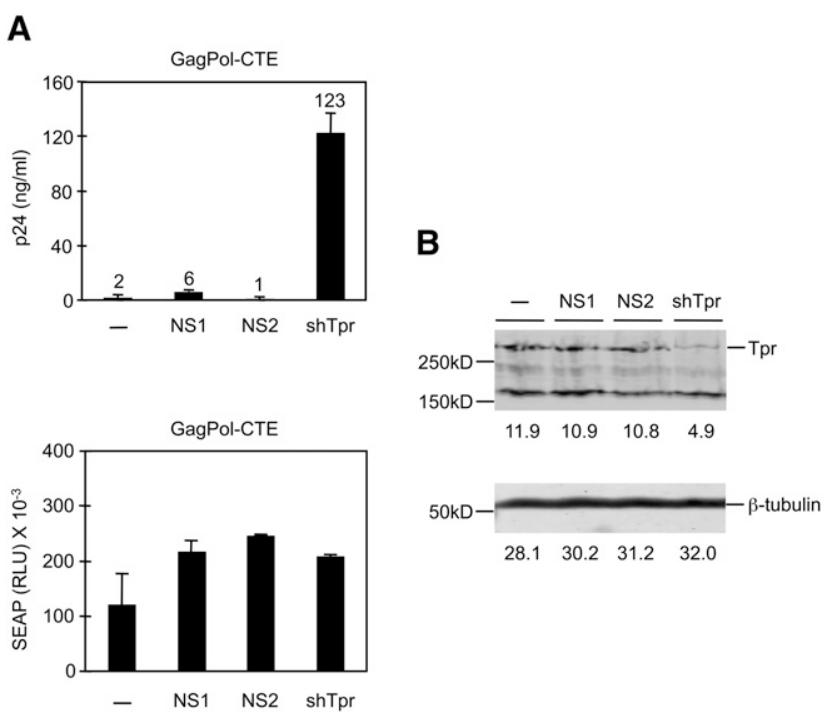

FIGURE 1. The effect of Tpr knockdown on p24 expression from a GagPol-CTE reporter plasmid. 293T cells $\left(1 \times 10^{6}\right)$ were transfected in $6-\mathrm{cm}$ dishes with $1.8 \mu \mathrm{g}$ of the pCMVGagPol-CTE reporter plasmid (pHR1361) and $0.09 \mu \mathrm{g}$ of pCMVSEAP (pHR1831); $(A)$ with or without $1 \mu \mathrm{g}$ of a plasmid expressing Tpr shRNA under the control of the human $\mathrm{H} 1$ promoter (pHR3068) targeting nucleotides 1376-1394 of TPR (Accession \# U69668) or nonspecific control shRNAs (NS1 and NS2, pHR2791 and pHR2842, respectively). Supernatants were collected at $72 \mathrm{~h}$ post-transfection, and p24 (upper panel) or SEAP (lower panel) levels in each sample were determined. The data represent the average from two independent transfections. (B) Validation of Tpr knockdown in transfected cells with quantitative Western blot analysis. Lysates from each of the transfected cells in A were separated on denaturing SDS-PAGE gels. Blots were probed with either anti-Tpr antibody (Santa Cruz) or anti- $\beta$-tubulin (Abcam). After incubating with appropriate secondary antibodies as described in Materials and Methods, blots were visualized using the Odyssey infrared imaging system and analyzed with the Odyssey software. The values under each lane represent the measured intensity. 
shown that expression and translation of the GagPol produced from this reporter can be monitored by measuring the accumulation of HIV p24 in the supernatant of the transfected cells (Smith et al. 1990; Bray et al. 1994; Guzik et al. 2001; Coyle et al. 2003; Jin et al. 2003; Bor et al. 2006; Li et al. 2006; Swartz et al. 2007). Such expression is absolutely dependent on the presence of a cis-acting element, either a CTE or an RRE. We first tested the CTE construct, where the mRNA interacts directly with Nxf1/Nxt1 (Guzik et al. 2001). As a control for transfection efficiency and specificity, we also cotransfected a plasmid expressing secreted alkaline phosphatase (SEAP) from a normally spliced mRNA (Berger et al. 1988). Expression from this plasmid can also be easily monitored by measuring SEAP levels in the supernatant.

The results of this experiment are shown in Figure 1, where it can be seen that expression of Tpr shRNA resulted in a very significant 60 -fold enhancement of p24 protein levels in the supernatants of transfected cells (Fig. 1A, top panel). In contrast, the levels of SEAP remained virtually the same (Fig. 1A, lower panel). Thus, there was a very striking differential effect on p24 expression from the intron-retaining GagPol-CTE mRNA, compared to SEAP expression from the completely spliced mRNA. To address potential nonspecific effects of shRNA expression, we also performed experiments with plasmids expressing two nonspecific shRNAs (NS1 and NS2). As can be seen in Figure $1 \mathrm{~A}$, these had only minimal effects on either p24 or SEAP expression.

\section{Expression of p24 is not enhanced by Tpr knockdown when the mRNA is exported through the Crm1 pathway}

As described above, Rev and the RRE can alternatively be used to achieve export and expression of the unspliced GagPol mRNA. In this case, the Crm1 pathway is used for export, and p24 expression is absolutely dependent on Rev that binds to the RRE and interacts with this export receptor (Smith et al. 1990). To analyze whether Tpr knockdown had an effect on Rev-RRE-mediated expression as well, we cotransfected cells with a GagPol-RRE reporter plasmid and the H1-Tpr shRNA plasmid, in the presence and absence of Rev. As before, the plasmid expressing SEAP from a spliced mRNA was also added as a normalization control. The results are shown in Figure 2A. Consistent with many previous studies, no significant p24 expression was observed with the RRE construct alone in the absence of Rev, whereas cotransfection of Rev led to high levels of p24 expression. Significantly, in contrast to the results in Figure 1, Tpr knockdown did not lead to an increase in p24, either in the absence or presence of Rev. Thus, taken together with the results from Figure 1, our results indicate that perturbation of Tpr affects expression from the unspliced GagPol mRNA only when it traffics on the Nxf1/Nxt1 pathway.
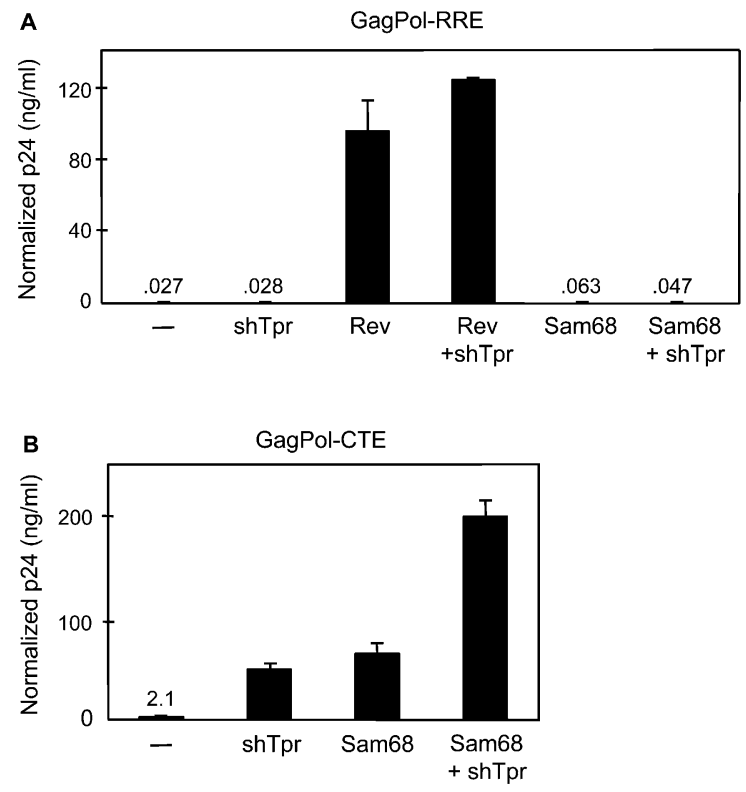

FIGURE 2. Tpr siRNA-mediated enhancement of p24 expression specifically requires the cis-acting CTE element. 293T cells $\left(1 \times 10^{6}\right)$ were transfected in 6-cm dishes with $1.8 \mu \mathrm{g}$ of either $(A)$ a pCMVGagPolRRE plasmid (pHR354) or (B) a pCMVGagPol-CTE plasmid (pHR1361) and plasmids expressing Tpr shRNA (pHR3068; $0.2 \mu \mathrm{g}$ ), Rev (pHR30; $0.4 \mu \mathrm{g}$ ), or Sam68 (pHR2208; $0.4 \mu \mathrm{g}$ ) in the combinations indicated. In all cases, $0.09 \mu \mathrm{g}$ of pCMVSEAP (pHR1831) was also transfected as a normalization control. Supernatants were collected at $72 \mathrm{~h}$ post-transfection and p24 and SEAP levels in each sample were determined. p24 values were then normalized for variations in SEAP levels. The data represent the average from two independent transfections.

\section{Expression of Sam68 and Tpr shRNA show an additive effect on p24 expression from the CTE plasmid but has no effect on the RRE reporter}

We have previously demonstrated that exogenous expression of the KH-domain RNA-binding protein Sam68 also enhances CTE-mediated, but not Rev/RRE-mediated expression in 293 cells using the GagPol reporters (Coyle et al. 2003). This effect was shown to be due to increased translation of the CTE-containing mRNA, whereas effects on nucleo-cytoplasmic export were minimal. Since both Tpr and Sam68 appear to be regulated by kinases and signal transduction (Matter et al. 2002; Coyle et al. 2003; Vomastek et al. 2008), we decided to determine the effect that a combination of Sam68 and Tpr shRNA expression would have on p24 expression from both the GagPol-CTE and GagPol-RRE reporter plasmids. As shown in Figure 2A, cotransfection of a plasmid that expressed Sam68 had no significant effects on p24 expressed from the GagPol-RRE plasmid, and no enhancement was seen when the Tap shRNA plasmid was cotransfected. The lack of effect of Sam68 on GagPol-RRE expression confirms our previously reported observations (Coyle et al. 2003). In contrast, when p24 expression from the GagPol-CTE plasmid was measured, coexpression of Tpr shRNA or Sam68 gave a significant 
increase in CTE-mediated expression, compared to shRNA and Sam68 alone. As seen before (Coyle et al. 2003), Sam68 alone was able to increase p24 to levels comparable to those seen with Rev/RRE. This is consistent with results from previous studies and is due to poor translation of the GagPol-CTE mRNA that can be rescued by Sam68 and other cellular cofactors for CTE function (Coyle et al. 2003; Jin et al. 2003; Bor et al. 2006; Li et al. 2006; Swartz et al. 2007). In addition, the combination of Sam68 expression and Tpr knockdown resulted in levels of p24 that were higher than those seen with Rev/RRE.

\section{The effects of Tpr shRNA expression are significantly reversed by expression of an siRNA-resistant form of Tpr}

We next wanted to further verify that the enhancement of CTE function seen with the Tpr shRNA plasmid was a direct consequence of Tpr knockdown. To this end, we used a commercial siRNA that targets a different region within TPR (nucleotides 4436-4454 in TPR Accession \#U69668). We also included a "scrambled" nonspecific (NS) siRNA in these experiments. To further address the specificity issue, we also included a Tpr expression plasmid that has an altered siRNA target region, making the Tpr mRNA produced from it resistant to siRNA inhibition.

The results of these experiments are shown in Figure 3. As before, targeting of Tpr gave a significant increase in p24 expression (Fig. 3A), and reduced levels of the endogenous Tpr were also seen (Fig. 3B, cf. first and second lanes from left). In the presence of a plasmid expressing Flagtagged wild type (wt) Tpr, almost the same levels of p24 were observed and no Flag-tagged protein was detected on the Western blot, indicating that newly expressed Tpr was efficiently targeted (Fig. 3B, third lane from left). In contrast, p24 expression was significantly reduced when the siRNA-resistant form of Tpr was expressed, and FLAG-Tpr was readily detected, confirming siRNA resistance (Fig. 3B, fourth lane from left). However, although p24 levels were significantly reduced as expected, the resistant form of Tpr did not reduce p24 expression back to the levels that were observed in the absence of siRNA. In the control experiment, using the nonspecific (NS) siRNA, no enhancement of p24 was observed when this siRNA was expressed alone, again demonstrating that only the specific siRNA enhanced p24 expression. However, in this case, significant enhancement of p24 expression was seen in cotransfections with both the wt and RNAi-resistant Tpr plasmids, and the Western blot showed that both of these proteins were efficiently expressed (Fig. 3B, the two last lanes at right). Thus, it is clear that overexpression of Tpr from these plasmids also leads to significant p24 enhancement. The reasons for this are unclear at the present time, but it has been observed in several experiments and seems to be a direct result of transient overexpression.
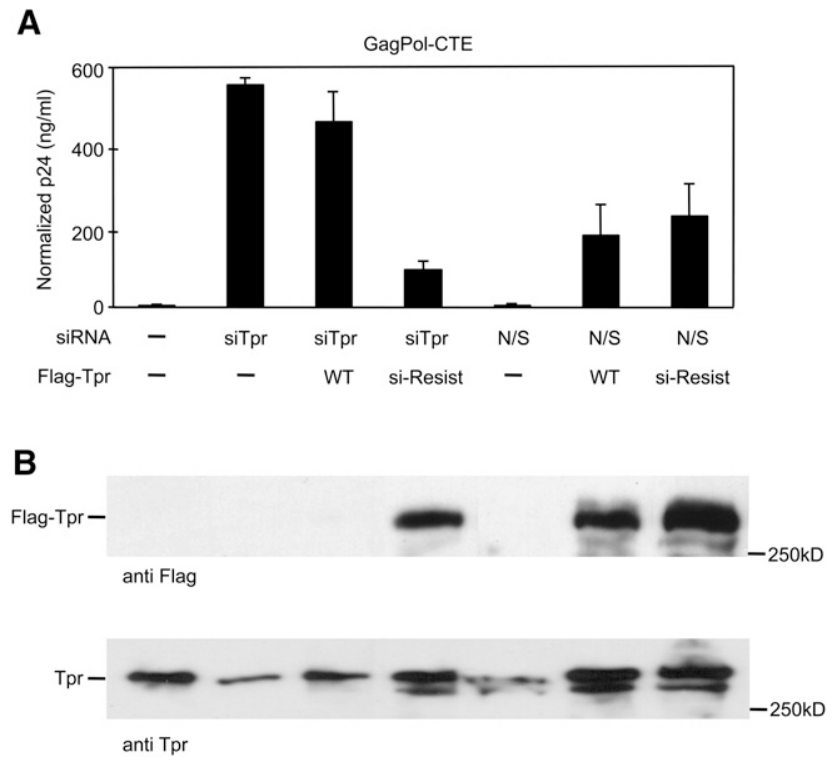

FIGURE 3. A Tpr mutant resistant to siRNA suppresses the effect of Tpr knockdown. 293T cells $\left(1 \times 10^{6}\right)$ were transfected in 6 -cm dishes with $1.8 \mu \mathrm{g}$ of the pCMVGagPol-CTE reporter plasmid (pHR1361), $0.09 \mu \mathrm{g}$ of pCMVSEAP (pHR1831), and $2 \mu \mathrm{g}$ of plasmids that expressed either wild-type (wt) FLAG-Tpr (pHR3120) or RNAiresistant FLAG-Tpr (pHR3122). Two micrograms of purified siRNA, which targets TPR nucleotides 4436-4454 (accession \# U69668) or a nonspecific control siRNA (N/S) were also co-transfected, as indicated. (A) Supernatants were collected at $72 \mathrm{~h}$ post-transfection, and p24 and SEAP levels from each sample were measured. p24 values were then normalized for variation in SEAP levels. Data represent the average from two independent transfections. (B) One hundred fifty micrograms of total lysate from each of the transfected 293T cell cultures in $A$ was separated on denaturing SDS-PAGE gels and analyzed by Western blotting. Blots were probed with either the M2 anti-Flag antibody (top) to detect FLAG-Tpr or a rabbit polyclonal Tpr antibody (bottom) to detect endogenous Tpr. The blots were visualized using ECL.

\section{Very small amounts of Tpr shRNA are sufficient to significantly enhance p24 levels but do not significantly down-regulate overall Tpr levels}

The experiments presented above suggested that a very large increase in p24 expression could be achieved even when endogenous Tpr levels were rather moderately reduced. To analyze this further, we performed a titration experiment using an shRNA. To this end, we made shRNAs in vitro, again targeting TPR nucleotides 4436-4454. Purified shRNA was titrated from $0.0016 \mu \mathrm{g}$ to $1.0 \mu \mathrm{g}$ in cells transfected with the GagPol-CTE- and SEAP-expressing plasmids. The minimum concentration of Tpr shRNA required to achieve maximal p24 enhancement was surprisingly low $(0.008 \mu \mathrm{g})$ (Fig. 4A). SEAP levels increased slightly (less than twofold), but at levels above $0.2 \mu \mathrm{g}$ there was a slight decrease compared to the control, likely due to nonspecific effects (Fig. 4B). Although only $0.008 \mu \mathrm{g}$ of Tpr shRNA plasmid was sufficient to maximize p24 enhancement with minimal effects on SEAP levels, Figure 4C shows 


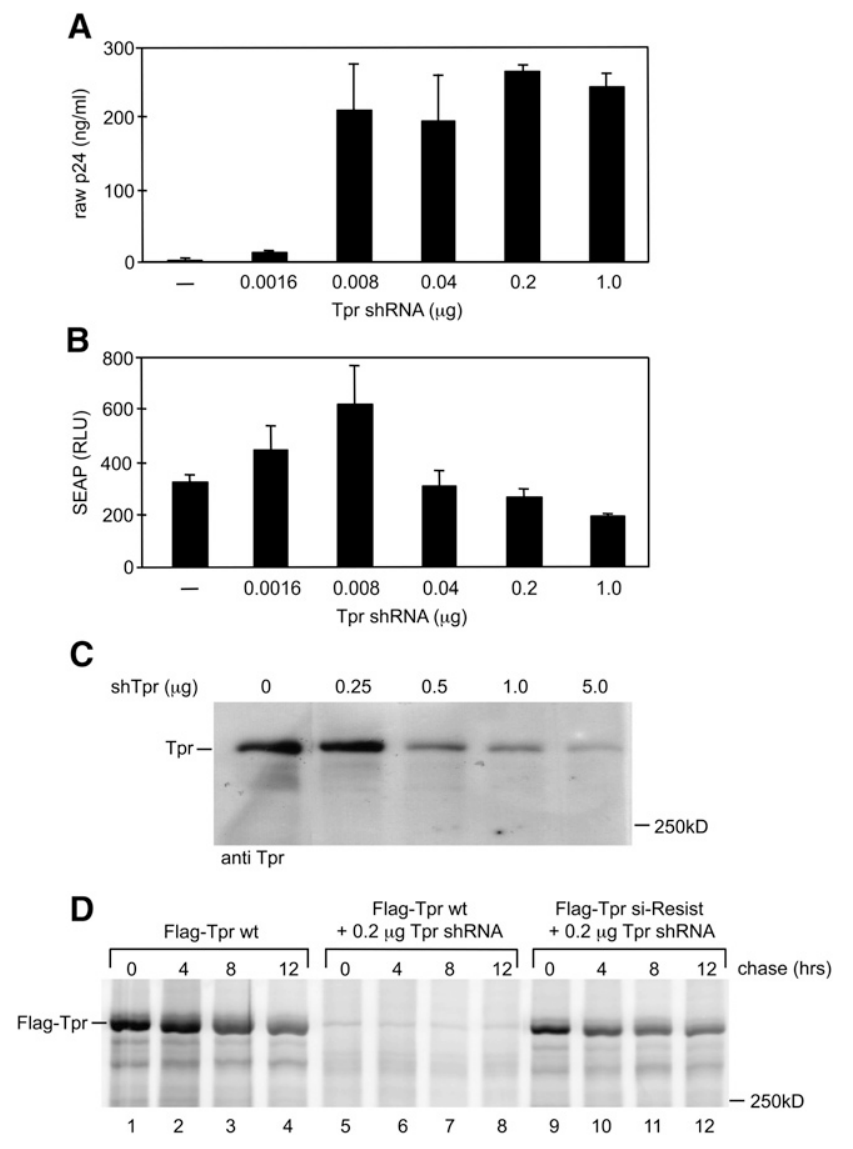

FIGURE 4. Dose response of the Tpr shRNA effect on GagPol-CTE expression. 293T cells were transfected in 6-cm dishes with $1.8 \mu \mathrm{g}$ of the pCMVGagPol-CTE reporter plasmid (pHR1361) and $0.09 \mu \mathrm{g}$ of pCMVSEAP (pHR1831) together with varying amounts of Tpr shRNA produced by transcription using T7 RNA polymerase $(0 \mu \mathrm{g}$ to $1.0 \mu \mathrm{g}$ as indicated). The shRNA targeted TPR nucleotides 44364454 (accession \#U69668). Supernatants were collected at $72 \mathrm{~h}$ posttransfection, and $(A)$ p24 or $(B)$ SEAP levels in each sample were determined. $(C)$ Western blot of endogenous Tpr levels in the presence of increasing amounts of Tpr shRNA. Total lysates from 293T cells $(150 \mu \mathrm{g}$ of protein) previously transfected with increasing amounts of in vitro transcribed Tpr shRNA (0 to $5.0 \mu \mathrm{g}$ ) were prepared at $72 \mathrm{~h}$, separated by SDS-PAGE, and analyzed by Western blotting. Endogenous Tpr was detected using a rabbit polyclonal antibody and visualized using ECL. $(D)$ Pulse-chase analysis of Tpr in the presence of Tpr shRNA. 293T cells in 6-cm dishes were transfected with wt FLAG-Tpr (pHR3120) or si-Resist FLAG-Tpr (pHR3122) plasmids in the presence or absence of $0.2 \mu \mathrm{g}$ of Tpr shRNA. At $48 \mathrm{~h}$ post-transfection, transfected cells were metabolically labeled for $3 \mathrm{~h}$ in the presence of ${ }^{35} \mathrm{~S}$ Trans-label (methionine/cysteine) and chased with complete media for either $0,4,8$, or $12 \mathrm{~h}$ and lysed. Equal amounts of lysate were used to immunoprecipitate wt FLAG-Tpr or si-Resist FLAG-Tpr with M2 anti-Flag antibody. IPs were analyzed by SDS-PAGE and a Molecular Dynamics PhosphorImager.

that $>30$-fold higher levels of Tpr shRNA were needed before the steady-state levels of endogenous Tpr were significantly knocked down.

To further analyze the effects of the Tpr shRNA on p24 expression, a 15-h pulse-chase experiment was carried out in 293 T cells that were transfected with plasmids expressing either wild-type (wt) or RNAi-resistant Tpr in the presence or absence of $0.2 \mu \mathrm{g}$ of Tpr shRNA. As shown in Figure 4C, a similar level of this shRNA $(0.25 \mu \mathrm{g})$ had little effect on the endogenous pool of Tpr over a 72 -h period. Figure 4D (lanes 1 and 9) shows that during a 3-h labeling period, the amounts of FLAG-Tpr produced from the Tpr wt plasmid in the absence of shRNA were similar to those made by the RNAi-resistant plasmid in the presence of shRNA. In contrast, lane 5 in Figure 4D shows that the Tpr shRNA completely abrogated wt FLAG-Tpr synthesis. Lanes 2-4 and lanes $10-12$ of this figure further show that in the 12-h chase period, the stability of the Tpr proteins expressed was the same for both plasmids.

This experiment indicates that levels of Tpr-targeted shRNA, which have little effect on the stable endogenous Tpr pool, can efficiently block the synthesis of the newly made Tpr molecules. Together with the results from Figure 4A,C, these results suggest that the knockdown of newly synthesized Tpr, which constitutes a minor portion of the total Tpr in the cell, is sufficient to results in a severalfold specific enhancement of p24 expression from the GagPol-CTE plasmid.

\section{Inhibition of Tpr synthesis leads to a significant increase in export of GagPol-CTE RNA}

To investigate the level at which Tpr regulation affected CTEmediated expression, we performed Northern blot analysis on total and cytoplasmic fractions from transfected cells. We have previously used this kind of analysis in multiple studies to show that either a CTE or the RRE in cis is required for export of the unspliced GagPol RNA (Smith et al. 1990; Bray et al. 1994; Guzik et al. 2001; Bor et al. 2006). In these studies, we have demonstrated that Rev and a functioning Crm1 pathway are essential for export of GagPol-RRE RNA. In contrast, export of GagPol-CTE RNA is mediated by the Nxf1 protein in a complex with the cofactor Nxt1. These proteins are endogenously expressed, enabling export of GagPol-CTE RNA without the addition of exogenous protein. Although Sam68 can significantly enhance expression from the CTE-containing RNA, we have as described above shown that this is a result of increased translation of the mRNA in the cytoplasm after export (Coyle et al. 2003).

To investigate whether Tpr directly affected export, we transfected cells with the GagPol-CTE plasmid alone, or in cotransfections with shRNA against Tpr (with or without Sam68). Total RNA and cytoplasmic RNA were prepared and analyzed as described in Materials and Methods. As a control, we also cotransfected GagPol-CTE with Nxfland Nxt1, since we have also previously shown that exogenously added Nxf1/Nxt1 does not increase export (Jin et al. 2003; Bor et al. 2006; Li et al. 2006; Swartz et al. 2007). In all cases, the cells were cotransfected with the SEAP-expressing plasmid as a transfection control. The results are shown in Figure 5A. We also performed a separate experiment in which the GagPol-RRE plasmid was transfected alone or in 
A
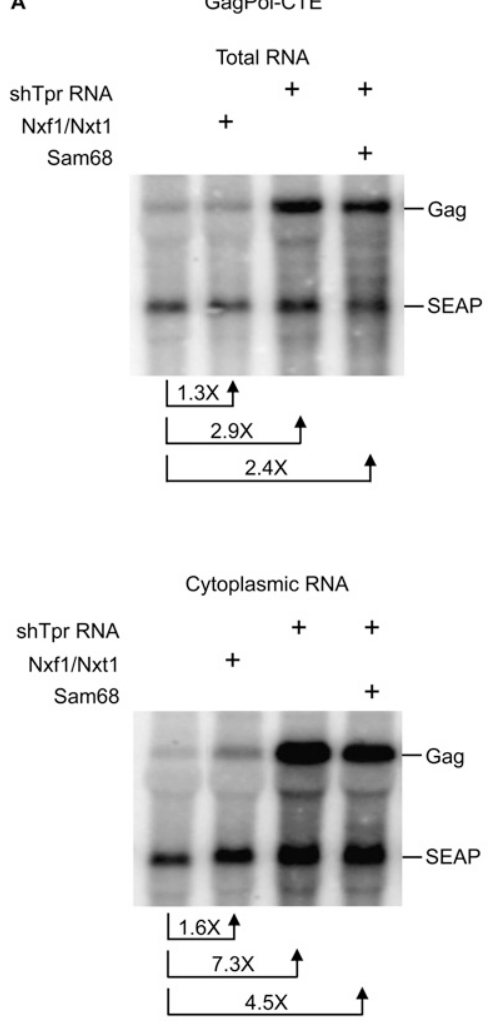

B

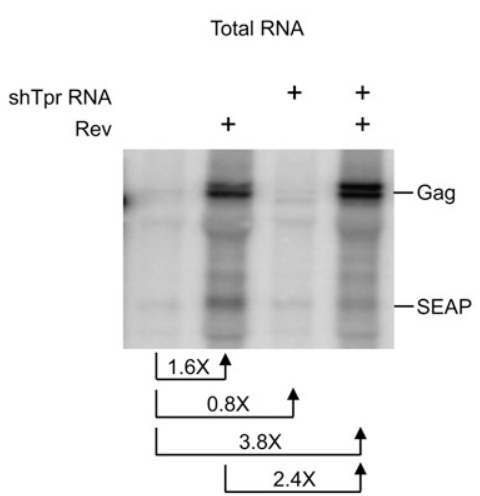

Cytoplasmic RNA

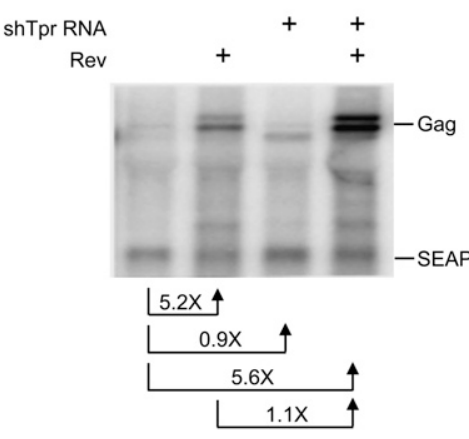

FIGURE 5. Northern blot analyses of total and cytoplasmic mRNA in transfected 293T cells. (A) Cells $\left(9 \times 10^{6}\right)$ in $15-\mathrm{cm}$ dishes were transfected with $15 \mu \mathrm{g}$ of pCMVGagPol-CTE (pHR1361) and $5 \mu \mathrm{g}$ of pCMVSEAP (pHR1831) with or without plasmids that expressed Nxf1 (pHR2128, $6 \mu \mathrm{g}$ ) and Nxt1 (pHR2283, $3 \mu \mathrm{g}$ ) or Sam68 (pHR2208, $3 \mu \mathrm{g}$ ), as indicated. Tpr shRNA was also transfected as indicated. (B) As a control, cells were transfected with $15 \mu \mathrm{g}$ of pCMVGagPol-RRE (pHR354) and $5 \mu \mathrm{g}$ of pCMVSEAP (pHR1831) in the absence or presence of $5 \mu \mathrm{g}$ of a plasmid expressing Rev (pHR30) as indicated. Tpr shRNA was also transfected as indicated. Sixty hours post-transfection, total and cytoplasmic poly $(\mathrm{A})^{+} \mathrm{mRNA}$ was isolated from the transfected cells. Blots containing the RNA samples were made and hybridized with ${ }^{32} \mathrm{P}$-labeled GagPol and SEAP probes. The values shown under the CTE panel $(A)$ represent the fold difference in the levels of GagPol-CTE mRNA in the various lanes compared with GagPol-CTE transfection alone. Similarly, the values shown under the RRE panel $(B)$ represent the fold difference in the levels of GagPol-RRE mRNA in the various lanes compared with GagPol-RRE transfection alone. All values were normalized using the SEAP band.

cotransfection with Rev, with or without Tpr shRNA. Again, total RNA and cytoplasmic RNA were analyzed (Fig. 5B).

Analysis of the blots shown in Figure 5 confirms previous results, showing that $\mathrm{Nxf1/Nxt1}$ do not give a significant increase in either total or cytoplasmic levels of GagPol-CTE RNA (Fig. 5A). In contrast, cotransfection with Tpr shRNA increased cytoplasmic levels of GagPol-CTE RNA 7.3-fold. This is slightly more than the increase seen in the presence of Rev in the case of GagPol-RRE (see Fig. 5B, lower panel). Thus, Tpr shRNA caused a significant increase in export of the GagPol-CTE RNA. Total GagPol-CTE RNA levels were also somewhat increased by shRNA targeting Tpr, as were the levels of GagPol-RRE RNA with Rev (Fig. 5A,B, upper panels). This may be due to a slightly lower stability of mRNA in the nuclear fraction, as has been described before for GagPol-RRE RNA. The addition of Sam68 did not increase levels of cytoplasmic RNA compared to what was seen with shRNA alone; rather, a small decrease was observed. This is consistent with our previously published studies showing that Sam68 increases cytoplasmic utilization, not export per se (Coyle et al. 2003).

In contrast to the results with GagPolCTE RNA, Tpr shRNA did not increase GagPol-RRE RNA in either the cytoplasmic or total fractions (Fig. 5B). In addition, Tpr shRNA did not increase levels of cytoplasmic RNA in the presence of Rev. This is consistent with the lack of effects of Tpr shRNA on GagPolRRE p24 expression in experiments with or without the plasmid that expressed Rev (see Fig. 2A). Taken together, these results indicate that Tpr specifically regulates the nucleo-cytoplasmic export of CTE-RNA.

\section{shRNA targeting Tpr also promotes the association of GagPol-CTE RNA with large polyribosomes}

In previous studies, we have demonstrated that although GagPol-CTE RNA is exported rather efficiently in 293T cells, it is inefficiently translated in the cytoplasm after export. We have also shown that moderate overexpression of either Sam68 or Nxf1 together with Nxt1 promotes GagPol protein synthesis (Coyle et al. 2003; Jin et al. 2003). In the case of Nxf1/Nxt1, we demonstrated that this is reflected in an increased association of the mRNA with large polyribosomes.

To investigate whether shRNA targeting Tpr, alone or in combination with Sam68 expression, affected association of the mRNA with ribosomes, we performed a polyribosome analysis on lysates of transfected cells (Fig. 6A-D). After sucrose fractionation, RNA from each of 12 fractions was isolated and analyzed by Northern blot using a Gag-specific probe. To each fraction, a small amount of in vitro transcribed gag RNA (IVT gag) was added as an internal standard for RNA quantification in each sample, thereby controlling for potential RNA degradation and variations between RNA sample preparations during isolation.

As shown in Figure 6, when the GagPol-CTE plasmid was transfected alone, the GagPol-CTE RNA was mainly detected in the fractions containing small polyribosomes (Fig. 6A), with only $9 \%$ observed in fractions containing larger polyribosomes, 
A

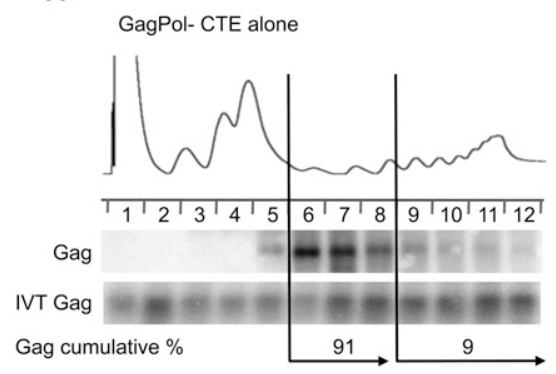

C

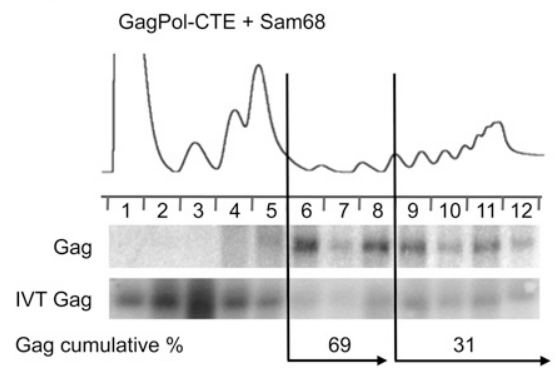

B

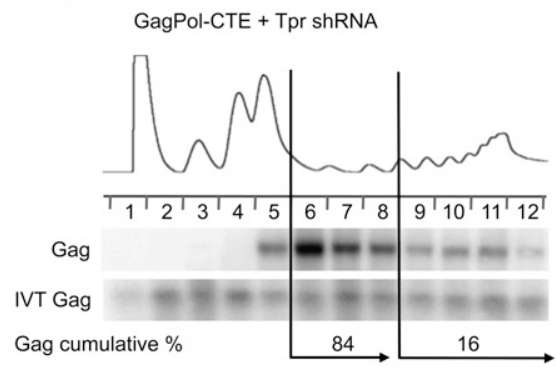

D

GagPol-CTE + Sam68 +Tpr shRNA

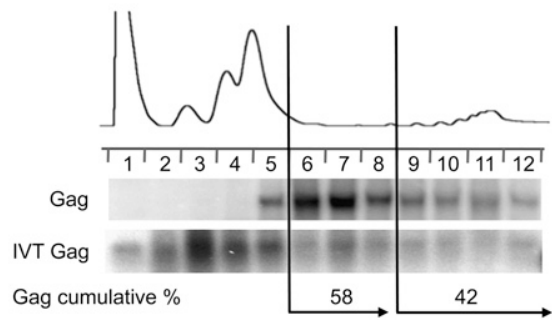

FIGURE 6. Polyribosome analysis of GagPol-CTE mRNA in $293 \mathrm{~T}$ cells transfected with a plasmid expressing Sam68 and/or in vitro transcribed Tpr shRNA. Cells $\left(9 \times 10^{6}\right)$ in $15-\mathrm{cm}$ dishes were transfected with $16 \mu \mathrm{g}$ of pCMVGagPol-CTE plasmid (pHR1361) and $0.825 \mu \mathrm{g}$ of pCMVSEAP (pHR1831) alone $(A)$ or in the presence of $4 \mu \mathrm{g}$ Tpr shRNA $(B), 3.3 \mu \mathrm{g}$ of a plasmid expressing Sam68 (pHR2208) $(C)$, or both $(D)$. Forty-eight hours after transfection, cytoplasmic fractions were prepared and separated over sucrose gradients by centrifugation, as described in the Materials and Methods. The gradients were fractionated, and the $\mathrm{OD}_{254}$ of each fraction was measured. An in vitro transcribed (IVT) gag RNA was added to each fraction, as a control for RNA recovery and degradation, before RNA was isolated from each fraction. The isolated RNA was then analyzed for GagPol-CTE mRNA by Northern blots. The intensity of the bands on the blots was quantified using a PhosphorImager and ImageQuant software. The measured intensity of each GagPol-CTE band was then corrected for recovery, using the IVT gag RNA band in each fraction. The values shown in each panel are the percentage of cumulative GagPol-CTE RNA detected in the light and heavy portions of the polysome fractions. This experiment was repeated three times with similar results. A single representative experiment is shown.

indicating inefficient translation. The addition of Tpr shRNA led to $16 \%$ of the GagPol-CTE RNA appearing in larger polyribosomes (Fig. 6B), whereas cotransfection with GagPol-CTE and the Sam68 plasmid increased this to 31\% (Fig. 6C). Thus, Tpr appears to have a slight effect on translation efficiency, but its effect is not as great as the effect of Sam68. With a combination of Tpr shRNA and Sam68, $42 \%$ of the RNA was now observed in the fractions containing large polysomes (Fig. 6D). This increase is greater than the effect of either the Tpr shRNA or Sam68 alone, consistent with the results seen in Figure 2B. Taken together, these results indicate that $\mathrm{Tpr}$ shRNA also promotes polyribosome association of the GagPol-CTE RNA, in addition to the effect on export (Fig. 5).

\section{Increased amounts of the Gag protein are synthesized in cells treated with Tpr shRNA, but protein stability is not affected}

The results above indicate that Tpr knockdown increases both GagPol-CTE RNA export and translation of this

mRNA in the cytoplasm. In combination, these effects are likely to cause the large enhancement in p24 levels that is observed when $\mathrm{Tpr}$ is perturbed. Although more unlikely, Tpr knockdown could also have effects on Gag protein stability after synthesis. To analyze this, we performed a pulse/chase analysis on transfected cells. Since the Gag proteins are eventually cleaved into different protein products, including $\mathrm{p} 24$, which complicates a direct analysis of effects on synthesis and stability, we performed this experiment using variants of the GagPol-CTE and GagPol-RRE plasmids that express a nonmyristoylated $\left(\mathrm{myr}^{-}\right)$protease negative $\left(\mathrm{pro}^{-}\right)$ form of the Gag protein. This is the result of two specific point mutations in the plasmids. Thus, all of the synthesized Gag protein remains in the cell and is not cleaved, facilitating a pulsechase analysis. We have used this construct in similar experiments in previous studies (Jin et al. 2003; Bor et al. 2006).

Cells were transfected with the GagPolCTE $\mathrm{myr}^{-}$pro $^{-}$plasmid alone or in cotransfections with either Sam68 or shRNA targeting Tpr. As a control, we also performed an experiment with a GagPol-RRE myr ${ }^{-}$pro $^{-}$plasmid, with or without a plasmid that expressed Rev. Thirty-six hours post-transfection, the cells were labeled for $15 \mathrm{~min}$ with ${ }^{35} \mathrm{~S}$ Trans-label (methionine/cysteine) and either harvested immediately or "chased" for $10 \mathrm{~h}$. Lysates were then made, and immunoprecipitation (IP) was performed with a monoclonal antibody against an epitope within the p24 portion of Gag. Before the IP, ${ }^{35}$ S-labeled GST-p24 was added as a control for IP recovery. After SDS-PAGE, radioactivity was detected using a PhosphorImager. As can be seen in Figure 7, significantly increased amounts of Pr55Gag were synthesized in the cotransfections with either Sam68 or Tpr shRNA, consistent with the above results (see Fig. 6). In each case, the protein appeared stable over the 10 -h chase period. As expected and consistent with previous studies, no Pr55 Gag was detected in the case of the GagPol-RRE plasmid in the absence of Rev, but a large amount of protein was detected when Rev was added. Again, the protein was stable throughout the 10-h chase period. Taken together, these results confirmed that knockdown of Tpr leads to increased translation of an unspliced CTE-containing mRNA, without any effects on protein stability. 


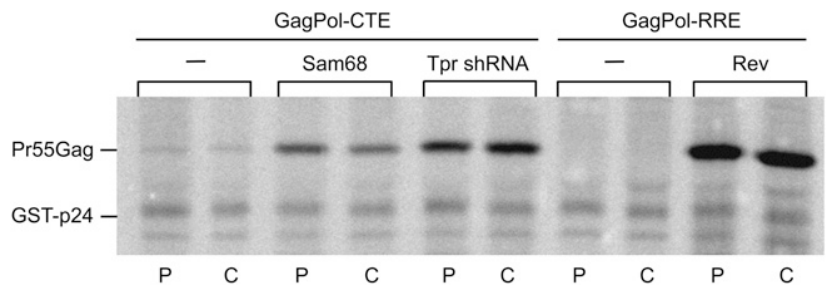

FIGURE 7. Pulse-chase analysis of the Pr55Gag protein expressed from pCMVGagPol-CTE $\mathrm{myr}^{-}$pro $^{-}$or pCMVGagPol-RRE myr pro $^{-}$in transfected $293 \mathrm{~T}$ cells. Cells $\left(3 \times 10^{6}\right)$ in $10-\mathrm{cm}$ dishes were transfected with $5 \mu \mathrm{g}$ of pCMVGagPol-CTE $\mathrm{myr}^{-} \mathrm{pro}^{-}$(pHR2900) with or without $1 \mu \mathrm{g}$ of a plasmid expressing Sam68 (pHR2208) or $0.2 \mu \mathrm{g}$ of Tpr shRNA. As a control, cells were also transfected with $5 \mu \mathrm{g}$ of pCMVGagPol-RRE $\mathrm{myr}^{-}$pro $^{-}$(pHR2899) with or without $1 \mu \mathrm{g}$ of pCMVRev (pHR30). Thirty-six hours post-transfection, cells were pulsed with ${ }^{35} \mathrm{~S}$ Trans-label (methionine/cysteine) for $15 \mathrm{~min}$ and chased for $10 \mathrm{~h}$. Lysates were made, ${ }^{35}$ S-labeled GST-p24 was added as a recovery control, and an IP was performed using an antip24 monoclonal antibody (183-H12-5C). The precipitates were analyzed on a 15\% SDS-PAGE using a PhosphorImager. The locations of the immunoprecipitated Pr55Gag and the control GST-p24 protein are indicated. (P) Pulse; (C) chase.

\section{DISCUSSION}

It is well established that unspliced and incompletely spliced mRNA is subject to specific restrictions at the level of nuclear export (Legrain et al. 1988; Chang and Sharp 1989). Many recent studies have shown that the NPC serves as a site for the control of transport substrates (for review, see Walde and Kehlenbach 2010). Studies in yeast have indicated that the nuclear pore basket protein, Mlp1, functions in the control of export of unspliced RNA (Galy et al. 2004; Fasken and Corbett 2009). By analogy, these results have pointed to a potential role for the mammalian Mlp1 ortholog, Tpr, in the regulation of mRNA export, but this has never been clearly demonstrated. Our results show for the first time that Tpr functions to regulate unspliced RNA with retained introns in mammalian cells, supporting the concept of an important role for Tpr in mRNA quality control.

We have previously shown that a CTE in an mRNA with retained introns directly recruits the export receptor Nxf1, in a complex that also includes Nxt1 (Guzik et al. 2001). In 293T cells, endogenous levels of Nxf1/Nxt1 are sufficient to allow significant export. However, in these cells, overexpression of Nxf1/Nxt1 leads to an increase in the translation of the CTE-RNA in the cytoplasm (Jin et al. 2003). In contrast, here we show that a very modest knockdown or increase in the levels of Tpr causes a significant increase in export of unspliced mRNA containing a CTE. Thus, the increase in export that occurs when Tpr levels are altered is not likely to be due to additional levels of endogenous Nxf1/Nxt1 being recruited to the mRNA. Rather, they speak for an additional level of restriction that is mediated, at least in part, by Tpr.

Intriguingly, perturbation of Tpr affected export of RNA with retained introns only when export was mediated by a CTE, which uses the Nxf1/Nxt1 pathway. In contrast, when the mRNA contained an RRE and was exported by Crm1, using Rev as an adapter, knockdown of Tpr had no effect. Tpr knockdown also did not lead to export of RRERNA, when Rev was not provided. These findings support the notion that mRNA export restrictions in mammalian cells differ as a function of the export pathway that is used. The specificity seen with Tpr speaks against a model whereby restricted RNA simply escapes control because of a general defect in Tpr function at the nuclear or NPC level. Thus, these results are in contrast to results obtained in yeast with Mlp1, where Mlp1 defects alone were reported to lead to "leakage" of unspliced mRNA out of the nucleus (Galy et al. 2004). This difference may be a reflection of the fact that higher eukaryotic systems regulate expression of mRNAs that have many alternatively spliced forms and multiple introns (Wang et al. 2008). Higher eukaryotes thus likely have a much more sophisticated regulation than yeast, with multiple levels of quality control, and correspondingly, multiple mechanisms to escape this control.

The lack of effect on mRNA exported by $\mathrm{Crm} 1$ that we observed in this study was somewhat unexpected, since we originally started our experiments based on the hypothesis that Tpr would be specifically involved in RNA export mediated by Crm1. This was based on previous studies suggesting a role for Tpr in Crm1-mediated protein export (Frosst et al. 2002). It is possible that specific functional interactions between Tpr and Nxf1/Nxt1 exist, which would not be in play when the unspliced mRNA is exported through the Rev/RRE axis that uses Crm1, independent of Nxf1/Nxt1.

Our results suggest that the Tpr may function differently in conjunction with $\mathrm{Crm} 1$ during protein export compared to RNA export. Alternatively, Rev and the RRE may serve to overcome Tpr-mediated restrictions through the recruitment of additional factors to the RNA. Although the Crm1 pathway for mRNA export has been most thoroughly studied in HIV and other viruses, it is clear that some cellular mRNAs are also exported with the help of Crm1 (Culjkovic et al. 2006; Prechtel et al. 2006; Schutz et al. 2006). Thus, the differences that we have observed between RRE- and CTE-mediated export may reflect differences in the way in which cellular mRNA intron surveillance and quality control are achieved when the mRNA is trafficked on different pathways.

Previous studies have suggested functional interactions between Mlp1 and Mex67/Mtr2 in yeast, since Mlp1 defects increase the effects of Mex67 temperature-sensitive mutations. This is of interest since Mex67 is the Nxf1 yeast ortholog and has been shown to be a major mRNA export factor (Segref et al. 1997; Katahira et al. 1999). Mlp1 has also been shown to interact with Nab2, a poly(A)-binding protein that also interacts with Mex67 (Green et al. 2003a; Fasken et al. 2008). Currently, no definitive mammalian ortholog for Nab2 has been identified. However, there is some evidence to suggest that one or more isoforms of the 
human/mouse poly(A)-binding proteins expressed from the gene $\mathrm{ZC} 3 \mathrm{H} 14$ may serve in this function (Leung et al. 2009). Also, several previous studies suggest a coupling between the polyadenylation machinery and mRNA export in mammalian cells (for review, see Zhao et al. 1999). More recently, the CPSF6 gene product (the CF $\mathrm{I}_{\mathrm{m}} 68$ protein) was reported to stimulate Nxf1-mediated mRNA export (Ruepp et al. 2009). It was suggested that the CF $I_{m} 68$ protein accompanies the RNP complex to the cytoplasm and that it is released in the cytoplasm during the initial stages of translation. In view of these studies, it will be of clear interest to explore potential physical and functional interactions between Tpr and CF $\mathrm{I}_{\mathrm{m}} 68$.

Another poly(A)-binding protein, the $\mathrm{KH}$-domain protein Sam68, which was shown in this and previous studies to enhance CTE function at the cytoplasmic level (Coyle et al. 2003), has been reported to stimulate mRNA 3' processing, resulting in increased gene expression (McLaren et al. 2004). Like Nab2, the function of Sam68 is regulated by mitogen-activated protein (MAP) kinases as well as other kinases (Matter et al. 2002; Coyle et al. 2003). The fact that overexpression of Sam68 and Tpr knockdown shows an additive effect on CTE function may be indicative of a cross talk between these two factors, which ultimately results in increased ribosome association and translation of proteins in the cytoplasm.

Our experiments demonstrate that only a very small decrease in overall levels of Tpr is needed for a significant enhancement of CTE export and expression. When only a small amount of Tpr shRNA was used, the effects on expression of a completely spliced mRNA (the SEAP RNA) were minimal, whereas higher levels caused a decrease in expression of this RNA. Thus, the effect seen at higher levels of knockdown is clearly a different effect from the one seen at lower levels. This may explain a previous report that showed a general decrease in mRNA export when Tpr function was perturbed (Shibata et al. 2002).

Our results may indicate that only newly synthesized Tpr protein is involved in the regulation of CTE-RNA export. Previous studies have suggested that there may be two "pools" of Tpr in mammalian cells. Specifically, image analysis has indicated that Tpr is present in the nucleoplasmic fraction, in association with splicing factors and other proteins, in addition to being present at the nuclear basket (Frosst et al. 2002). One potential model to explain our observations is that this more "dynamic" fraction of Tpr interacts with mRNPs at the transcriptional level, before and during the splicing process, and that this interaction contributes to cytoplasmic retention until splicing has been completed. The inhibitory effects that were seen on completely spliced mRNA when higher levels of Tpr shRNA were used could then be a reflection of an effect on the structural Tpr nuclear basket component. This component would be expected to be increasingly compromised when levels of Tpr are more drastically reduced.
We observed a significant increase in p24 expression not only in Tpr knockdown experiments, but also when this protein was moderately overexpressed (see Fig. 3). Such apparently "paradoxical" effects, where both knockdown and overexpression lead to a similar phenotype, are not unprecedented. For example, it has been shown that in some cases, both reduced and increased amounts of a factor involved in transcription can result in the same phenotype, presumably because of squelching of limiting cofactors (for an example, see Drewelus et al. 2010). We thus hypothesize that an increase in Tpr synthesis may lead to squelching of one or more cellular proteins that are also involved in mRNA quality control. This suggests the possibility of a complex RNA gatekeeping function, involving other factors in addition to Tpr.

In addition to the effects of Tpr on export, the mRNA also appears to be affected at the cytoplasmic level, since Tpr knockdown also leads to an increase in association of CTE-RNA with large polyribosomal complexes. Sam68 also increases polyribosome association of CTE-containing mRNA. However, Sam68 does not increase export, either alone (Coyle et al. 2003) or in combination with shRNA targeting Tpr. It is also interesting that the combination of Tpr shRNA and Sam68 expression causes more CTE-RNA to be associated with polyribosomes than when either is expressed alone. This suggests that the mechanisms that allow more polyribosome association when Tpr is knocked down may be mechanistically different from the Sam68 effect. We have previously demonstrated that modest overexpression of Nxf1/Nxt1 as well as the splicing SR protein 9G8 give rise to a similar phenotype as overexpression of Sam68 (Swartz et al. 2007). Together these results support the hypothesis that important couplings exist between splicing, export, and translation of mRNA in the cytoplasm.

In the yeast system, many studies have provided evidence for couplings that start at the level of transcription, and it has been proposed that Mlp1 associates with newly transcribed mRNA at the chromatin level (for review, see Fasken and Corbett 2009). A very recent study involving the Drosophila Tpr ortholog, Megator, shows that this protein, in conjunction with nucleoporin Nup153, binds to transcriptionally active chromatin regions (Vaquerizas et al. 2010). The authors propose that this binding is reflective of chromosomal organization involved in gene expression control. In view of these experiments and the results presented here, we would like to suggest that a dynamic functional pool of Tpr may associate with the CTE-mRNA as early as at the chromatin level, enabling a functional regulation at many steps in post-transcriptional gene regulation.

\section{MATERIALS AND METHODS}

\section{Plasmids}

Most of the plasmids used in this study have been previously described. These are the HIV-1 reporter constructs 
pCMVGagPol-RRE (pHR354) and pCMVGagPol-CTE (pHR1361) (Srinivasakumar et al. 1997); pCMVRev (pHR30) (Smith et al. 1993); pCMVNxf1 (pHR2128), a plasmid that expresses the Tap/ Nxf1 protein (amino acids 61 to 619) (Yoon et al. 1997; Guzik et al. 2001); pcDNA3FLAGNXT1 (pHR2283), a plasmid that expresses a Flag-tagged Nxt1 protein (Black et al. 1999); pcDNA3FSam68 (pHR2208), a plasmid that expresses a Flagtagged Sam68 (Lin et al. 1997); pCMVSEAP (pHR1831), a plasmid that expresses secreted alkaline phosphatase (Berger et al. 1988); pCMVGagPolRRE myr $^{-}$pro $^{-}$(pHR2899) and pCMVGagPolCTE $\mathrm{myr}^{-}$pro $^{-}$(pHR2900), plasmids that contain inactivating point mutations in the myristoylation signal and protease region of the HIV gagpol gene; pGEXp24 (pHR163), a plasmid that expresses glutathione $S$-transferase (GST)-p24 (Jin et al. 2003); and pGEMgagBstHII/PstI (pHR2654), a plasmid used to prepare in vitro transcribed gag (Bor et al. 2006).

The H1-RNA promoter plasmid (pHR2790) was constructed essentially as previously described (Brummelkamp et al. 2002). The H1-RNA promoter sequence was amplified from $293 \mathrm{~T}$ cell genomic DNA with Deep Vent DNA polymerase (New England Biolabs), using the oligonucleotide 5'-CCATGGAATTCGAACGC TGACGTC-3' (\#969; the EcoRI site is underlined) as the forward primer, and the oligonucleotide 5'-GCAAGCTTAGATCTGTG GTCTCATACAGAACTTATAAGATTCC-3' (\#970; the BglII site is underlined) as the reverse primer. The resulting 239-bp PCR fragment was cloned into the EcoRV site of pBluescript II SK(+) (Stratagene), and the recombinant plasmids were transformed into Escherichia coli DH5 $\alpha$-competent cells. Plasmids isolated from the resulting colonies were screened by EcoRI and HindIII restriction digest to identify a clone in which the HindIII site present in the polylinker of pBlusecript II $\mathrm{SK}(+)$ is located downstream from the H1-RNA promoter. The base pair distance between BglII (derived from oligonucleotide \#970) and HindIII sites in this orientation allows a more efficient restriction cleavage by BgIII and HindIII restriction enzymes than that of the published pSUPER vector (Brummelkamp et al. 2002). To construct pH1shTpr (pHR3068), which expresses an shRNA targeting TPR, two complementary oligonucleotides,

5' -GATCCCCGTGGAAGCCAAAGCACCAATTCAAGAGATTGG TGCTTTGGCTTCCACTTTTTGGAAA-3' (\#1145) and 5'-AGCTTTTCCAAAAAGTGGAAGCCAAAGCACCAATCTCTT GAATTGGTGCTTTGGCTTCCACGGG-3' (\#1146),

were annealed to yield a duplex containing $19 \mathrm{nt}$ of the target (underlined, nucleotides 1376 to 1394 TPR accession \#U69668), a 9-base loop sequence for hairpin formation, followed by the 19-nt "inverted" target sequence. BamH1- and HindIII-compatible overhangs were introduced at each end of the oligonucleotide to facilitate ligation into the $\mathrm{pH} 1-\mathrm{RNA}$ promoter plasmid. The plasmids NS1 and NS2 (pHR2791 and pHR2842, respectively), expressing nontargeting shRNA, were constructed similarly to $\mathrm{pH} 1$-shTpr. These plasmids were used for the experiments presented in Figures 1 and 2.

The plasmids expressing Flag-tagged Tpr (pcDFLAG Tpr, pHR3120) and Flag-tagged Tpr that is resistant to siRNA targeting TPR (nucleotides 4436-4454; accession \# U69668; pHR3122), were kindly provided by Vinay K. Nandicoori and Michael Weber (University of Virginia). The plasmid expressing siRNA-resistant Tpr was made by introducing synonymous mutations into the target region. The plasmid expressing the eGFP-Tpr fusion pro- tein, peGFP-Tpr (pHR2955), was a gift from Larry Gerace (The Scripps Research Institute, La Jolla, CA).

\section{Source of commercial siRNA used in this study}

The experiments presented in Figure 3 were performed using commercial siRNA duplexes (QIAGEN) targeted to TPR nucleotides 4436-4454 (accession \#U69668) or a nonspecific control siRNA (Dharmacon).

\section{Production by in vitro transcription of short hairpin (sh) RNA for TPR RNAi}

A construct was designed to express an shRNA targeting TPR nucleotides 4436-4454 (accession \#U69668). Two complementary oligonucleotides,

\section{5'-TAATACGACTCACTATAGCACAACAGGATAAGGTTAAAG TTCTCTTAACCTTATCCTGTTGTGCTT-3' (\#1214) and 5'-AAGCACAACAGGATAAGGTTAAGAGAACTTTAACCTTAT CCTGTTGTGCTATAGTGAGTCGTATTA (\#1213),}

were annealed to form a DNA duplex that served as a T7 in vitro transcription template. The annealed duplex contains a T7 RNA polymerase promoter at one end (underlined), followed by 19 bases of the shTpr target (double underlined), a 9-base loop sequence, and an inverted repeat for the 19 bases of the shTpr target. In a final volume of $1 \mathrm{~mL}$, each in vitro transcription reaction consisted of $0.1 \mu \mathrm{M}$ annealed DNA duplex, $40 \mathrm{mM}$ Tris- $\mathrm{HCl}(\mathrm{pH}$ 7.9), $6 \mathrm{mM}$ $\mathrm{MgCl}_{2}, 2 \mathrm{mM}$ spermidine, $10 \mathrm{mM}$ DTT, $2.5 \mathrm{mM}$ rNTPs, $0.8 \mathrm{U} / \mu \mathrm{L}$ RNasin, and $20 \mu \mathrm{L}$ of T7 RNA polymerase. After incubation for $5 \mathrm{~h}$ at $40^{\circ} \mathrm{C}$, 2 units of RNase-free DNase I was added and the reaction was incubated for $45 \mathrm{~min}$ at $40^{\circ} \mathrm{C}$. Phenol/chloroform-extracted reaction mixture was ethanol-precipitated and resuspended in 50 $\mu \mathrm{L}$ of DEPC-treated water, and the in vitro transcribed shRNA was purified using a Chroma Spin-30 column according to the manufacturer's instructions (Clontech). The resulting shRNA was used for the experiments presented in Figures 4-7.

\section{Cell lines and transient transfections}

293T/17 cells (Pear et al. 1993) were maintained in Iscove's Modified Dulbecco's medium supplemented with $10 \%$ bovine calf serum. 293T/17 cells were transfected by using a calcium phosphate transfection protocol (Graham and van der Eb 1973). Transfections were performed with the amounts of plasmids and si/shRNA described in the figure legends.

\section{p24 ELISA and SEAP assay}

Supernatants from transfected cells were collected at $72 \mathrm{~h}$ posttransfection and subjected to a short spin in a microcentrifuge to remove residual cells and debris. Expression levels of p24 were determined by an ELISA protocol using a p24 monoclonal antibody (183 H12-5C) and pooled human anti-HIV immunoglobulin G (Wehrly and Chesebro 1997). The p24 antibody was obtained from the AIDS Research and Reference Reagent Program and was contributed by Bruce Chesebro (National Institute of Allergy and Infectious Diseases-Rocky Mountain Laboratories). SEAP activity in the supernatants was measured with the Phospha-Light Chemiluminescent Reporter Kit (Tropix). 


\section{Western blot analysis and antibodies}

Western blot analysis was performed essentially as previously described (Hammarskjöld et al. 1986). In brief, lysates from transfected cell were separated by electrophoresis on $6 \%$ SDS-polyacrylamide gel and transferred to an Immobilon-P membrane (Millipore). For detection of the FLAG-Tpr protein, the blots were probed with a 1:5000 dilution of M2 anti-Flag monoclonal antibody (Sigma). For detection of endogenous Tpr protein, the blots were probed with a rabbit polyclonal Tpr antibody raised against amino acid residues 2095-2348 (Frosst et al. 2002). Blots were developed using a horseradish peroxidase-coupled secondary antibody and the enhanced chemiluminescence (ECL) system (GE Health, Amersham Biosciences). To detect proteins using the Odyssey infrared imaging system (LI-COR), lysates from transfected cells were resolved in $8 \%$ SDS-PAGE and transferred to an Immobilon-FL. Membranes were probed with a mouse anti-Tpr monoclonal antibody (1:200 dilution; Santa Cruz), followed by incubating with a goat anti-mouse IgG antibody-IRDye 800 (1:25,000 dilution; LI-COR). As a loading control, the blot was also probed with a rabbit anti- $\beta$-tubulin (1:10,000 dilution; Abcam), washed, and probed with a goat antirabbit IgG-IRDye 680 (1:25,000 dilution; LI-COR). The blots were scanned on the Odyssey infrared imager. Protein levels were quantified with the Odyssey software.

\section{Polyribosome analysis}

The polyribosome analysis used for the detection of GagPol mRNA was performed essentially as previously described (Jin et al. 2003; Bor et al. 2006).

\section{RNA fractionation and Northern blot analysis}

The methods used for nuclear and cytoplasmic RNA extraction, poly(A) mRNA selection, and Northern blot analysis were previously described (Hammarskjöld et al. 1986, 1994). 293T cells were harvested at $65 \mathrm{~h}$ post-transfection. A SacI-BglII (nucleotides 682-2093) fragment of the HIV-1 BH10 clone and a BamHI fragment of the human SEAP cDNA (nucleotides 213-1698) were labeled with $\left[\alpha-{ }^{32} \mathrm{P}\right] \mathrm{dCTP}$ by using the Rediprime II Kit (GE Healthcare, Amersham Biosciences). Northern blots were quantified using the Molecular Dynamics PhosphorImager and ImageQuant analysis software.

\section{${ }^{35} \mathrm{~S}$ labeling and immunoprecipitations}

293T cells were transfected with pCMVGagPol-CTE myr ${ }^{-}$pro $^{-}$with or without pcDNAFLAGSam68 or pH1shTpr; or pCMVGagPolRRE myr $^{-}$pro $^{-}$with or without pCMVRev. At $36 \mathrm{~h}$ posttransfection, cells were washed twice with methionine and cysteinefree Dulbecco's modified Eagle's medium (GIBCO/Invitrogen) and then incubated for $15 \mathrm{~min}$ at $37^{\circ} \mathrm{C}$ in labeling medium containing $200 \mu \mathrm{Ci}$ of ${ }^{35} \mathrm{~S}$ Trans-label (ICN Biochemicals). Cells were then washed with normal medium and incubated for $10 \mathrm{~h}$. At the end of incubation, cell lysates were made and IPs were performed as previously described (Jin et al. 2003; Bor et al. 2006).

\section{ACKNOWLEDGMENTS}

This work was supported by NIH grants CA097095, GM087651, and AI054335. The expert technical assistance of Susan Prasad is gratefully acknowledged. We also thank Vinay K. Nandicoori (University of Virginia), Michael Weber (University of Virginia), and Larry Gerace (The Scripps Research Institute, La Jolla, CA) for supplying materials used in this study. Salary support for M.L.H. and D.R. was provided by the Charles H. Ross Jr. and Myles H. Thaler Endowments at the University of Virginia.

Received December 23, 2010; accepted April 18, 2011.

\section{REFERENCES}

Berger J, Hauber J, Hauber R, Geiger R, Cullen BR. 1988. Secreted placental alkaline phosphatase: a powerful new quantitative indicator of gene expression in eukaryotic cells. Gene 66: 1-10.

Black BE, Levesque L, Holaska JM, Wood TC, Paschal BM. 1999. Identification of an NTF2-related factor that binds Ran-GTP and regulates nuclear protein export. Mol Cell Biol 19: 8616-8624.

Bor Y, Swartz J, Morrison A, Rekosh D, Ladomery M, Hammarskjold ML. 2006. The Wilms' tumor 1 (WT1) gene (+KTS isoform) functions with a CTE to enhance translation from an unspliced RNA with a retained intron. Genes Dev 20: 1597-1608.

Bray M, Prasad S, Dubay JW, Hunter E, Jeang KT, Rekosh D, Hammarskjold ML. 1994. A small element from the Mason-Pfizer monkey virus genome makes human immunodeficiency virus type 1 expression and replication Rev-independent. Proc Natl Acad Sci 91: $1256-1260$.

Brummelkamp TR, Bernards R, Agami R. 2002. A system for stable expression of short interfering RNAs in mammalian cells. Science 296: $550-553$.

Carmody SR, Tran EJ, Apponi LH, Corbett AH, Wente SR. 2010. The mitogen-activated protein kinase Slt 2 regulates nuclear retention of non-heat shock mRNAs during heat shock-induced stress. Mol Cell Biol 30: 5168-5179.

Chang DD, Sharp PA. 1989. Regulation by HIV Rev depends upon recognition of splice sites. Cell 59: 789-795.

Cordes VC, Reidenbach S, Rackwitz HR, Franke WW. 1997. Identification of protein $\mathrm{p} 270 / \mathrm{Tpr}$ as a constitutive component of the nuclear pore complex-attached intranuclear filaments. J Cell Biol 136: 515-529.

Coyle JH, Guzik BW, Bor YC, Jin L, Eisner-Smerage L, Taylor SJ, Rekosh D, Hammarskjöld ML. 2003. Sam68 enhances the cytoplasmic utilization of intron-containing RNA and is functionally regulated by the nuclear kinase Sik/BRK. Mol Cell Biol 23: 92103.

Culjkovic B, Topisirovic I, Skrabanek L, Ruiz-Gutierrez M, Borden KL. 2006. eIF4E is a central node of an RNA regulon that governs cellular proliferation. J Cell Biol 175: 415-426.

Drewelus I, Gopfert C, Hippel C, Dickmanns A, Damianitsch K, Pieler T, Dobbelstein M. 2010. p63 antagonizes Wnt-induced transcription. Cell Cycle 9: 580-587.

Erkmann JA, Kutay U. 2004. Nuclear export of mRNA: From the site of transcription to the cytoplasm. Exp Cell Res 296: 12-20.

Fasken MB, Corbett AH. 2009. Mechanisms of nuclear mRNA quality control. RNA Biol 6: 237-241.

Fasken MB, Stewart M, Corbett AH. 2008. Functional significance of the interaction between the mRNA-binding protein, Nab2, and the nuclear pore-associated protein, Mlp1, in mRNA export. J Biol Chem 283: 27130-27143.

Fornerod M, Ohno M, Yoshida M, Mattaj IW. 1997. CRM1 is an export receptor for leucine-rich nuclear export signals. Cell 90: 1051-1060.

Forrest ST, Barringhaus KG, Perlegas D, Hammarskjöld ML, McNamara CA. 2004. Intron retention generates a novel Id3 isoform that inhibits vascular lesion formation. J Biol Chem 279: 32897-32903.

Frosst P, Guan T, Subauste C, Hahn K, Gerace L. 2002. Tpr is localized within the nuclear basket of the pore complex and has a role in nuclear protein export. J Cell Biol 156: 617-630. 
Galante PA, Sakabe NJ, Kirschbaum-Slager N, de Souza SJ. 2004. Detection and evaluation of intron retention events in the human transcriptome. RNA 10: 757-765.

Galy V, Gadal O, Fromont-Racine M, Romano A, Jacquier A, Nehrbass U. 2004. Nuclear retention of unspliced mRNAs in yeast is mediated by perinuclear Mlp1. Cell 116: 63-73.

Graham FL, van der Eb AJ. 1973. A new technique for the assay of infectivity of human adenovirus 5 DNA. Virology 52: 456-467.

Green DM, Johnson CP, Hagan H, Corbett AH. 2003a. The C-terminal domain of myosin-like protein 1 (Mlplp) is a docking site for heterogeneous nuclear ribonucleoproteins that are required for mRNA export. Proc Natl Acad Sci 100: 1010-1015.

Green RE, Lewis BP, Hillman RT, Blanchette M, Lareau LF, Garnett AT, Rio DC, Brenner SE. 2003b. Widespread predicted nonsensemediated mRNA decay of alternatively-spliced transcripts of human normal and disease genes. Bioinformatics (Suppl 1) 19: i118-i121.

Grüter P, Tabernero C, von Kobbe C, Schmitt C, Saavedra C, Bachi A, Wilm M, Felber BK, Izaurralde E. 1998. TAP, the human homolog of Mex67p, mediates CTE-dependent RNA export from the nucleus. Mol Cell 1: 649-659.

Guzik BW, Levesque L, Prasad S, Bor YC, Black BE, Paschal BM, Rekosh D, Hammarskjöld ML. 2001. NXT1 (p15) is a crucial cellular cofactor in TAP-dependent export of intron-containing RNA in mammalian cells. Mol Cell Biol 21: 2545-2554.

Hadzopoulou-Cladaras M, Felber BK, Cladaras C, Athanassopoulos A, Tse A, Pavlakis GN. 1989. The rev (trs/art) protein of human immunodeficiency virus type 1 affects viral mRNA and protein expression via a cis-acting sequence in the env region. J Virol 63: 1265-1274.

Hammarskjöld ML. 1997. Regulation of retroviral RNA export. Semin Cell Dev Biol 8: 83-90.

Hammarskjöld ML, Wang S-C, Klein G. 1986. High-level expression of the Epstein-Barr virus EBNA1 protein in CV1 cells and human lymphoid cells using a SV40 late replacement vector. Gene 43: 4150.

Hammarskjöld ML, Heimer J, Hammarskjold B, Sangwan I, Albert L, Rekosh D. 1989. Regulation of human immunodeficiency virus env expression by the rev gene product. J Virol 63: 1959-1966.

Hammarskjöld ML, Li H, Rekosh D, Prasad S. 1994. Human immunodeficiency virus env expression becomes Rev-independent if the env region is not defined as an intron. J Virol 68: 951-958.

Jin L, Guzik BW, Bor YC, Rekosh D, Hammarskjöld ML. 2003. Tap and NXT promote translation of unspliced mRNA. Genes Dev 17: 3075-3086.

Katahira J, Strasser K, Podtelejnikov A, Mann M, Jung JU, Hurt E. 1999. The Mex67p-mediated nuclear mRNA export pathway is conserved from yeast to human. EMBO J 18: 2593-2609.

Krull S, Thyberg J, Bjorkroth B, Rackwitz HR, Cordes VC. 2004. Nucleoporins as components of the nuclear pore complex core structure and Tpr as the architectural element of the nuclear basket. Mol Biol Cell 15: 4261-4277.

Legrain P, Seraphin B, Rosbash M. 1988. Early commitment of yeast pre-mRNA to the spliceosome pathway. Mol Cell Biol 8: 37553760 .

Leung SW, Apponi LH, Cornejo OE, Kitchen CM, Valentini SR, Pavlath GK, Dunham CM, Corbett AH. 2009. Splice variants of the human $\mathrm{ZC} 3 \mathrm{H} 14$ gene generate multiple isoforms of a zinc finger polyadenosine RNA binding protein. Gene 439: 71-78.

Li Y, Bor YC, Misawa Y, Xue Y, Rekosh D, Hammarskjöld ML. 2006. An intron with a constitutive transport element is retained in a Tap messenger RNA. Nature 443: 234-237.

Lin Q, Taylor SJ, Shalloway D. 1997. Specificity and determinants of Sam68 RNA binding. Implications for the biological function of $\mathrm{K}$ homology domains. J Biol Chem 272: 27274-27280.

Malim MH, Hauber J, Le SV, Maizel JV, Cullen BR. 1989. The HIV-1 rev trans-activator acts through a structured target sequence to activate nuclear export of unspliced viral mRNA. Nature 338: 254 257.
Marinescu V, Loomis PA, Ehmann S, Beales M, Potashkin JA. 2007. Regulation of retention of FosB intron 4 by PTB. PLoS ONE 2: e828. doi: 10.1371/journal.pone.0000828.

Matter N, Herrlich P, Konig H. 2002. Signal-dependent regulation of splicing via phosphorylation of Sam68. Nature 420: 691-695.

McLaren M, Asai K, Cochrane A. 2004. A novel function for Sam68: Enhancement of HIV-1 RNA 3' end processing. RNA 10: 11191129.

Mollet IG, Ben-Dov C, Felicio-Silva D, Grosso AR, Eleuterio P, Alves R, Staller R, Silva TS, Carmo-Fonseca M. 2010. Unconstrained mining of transcript data reveals increased alternative splicing complexity in the human transcriptome. Nucleic Acids Res 38: 4740-4754.

Ogert RA, Lee LH, Beemon KL. 1996. Avian retroviral RNA element promotes unspliced RNA accumulation in the cytoplasm. J Virol 70: $3834-3843$.

Otero GC, Harris ME, Donello JE, Hope TJ. 1998. Leptomycin B inhibits equine infectious anemia virus Rev and feline immunodeficiency virus rev function but not the function of the hepatitis B virus posttranscriptional regulatory element. J Virol 72: 75937597.

Pear WS, Nolan GP, Scott ML, Baltimore D. 1993. Production of high-titer helper-free retroviruses by transient transfection. Proc Natl Acad Sci 90: 8392-8396.

Prechtel AT, Chemnitz J, Schirmer S, Ehlers C, Langbein-Detsch I, Stulke J, Dabauvalle MC, Kehlenbach RH, Hauber J. 2006. Expression of CD83 is regulated by HuR via a novel cis-active coding region RNA element. J Biol Chem 281: 10912-10925.

Ruepp MD, Aringhieri C, Vivarelli S, Cardinale S, Paro S, Schumperli D, Barabino SM. 2009. Mammalian pre-mRNA 3' end processing factor CF I m 68 functions in mRNA export. Mol Biol Cell 20: 5211-5223.

Schutz S, Chemnitz J, Spillner C, Frohme M, Hauber J, Kehlenbach RH. 2006. Stimulated expression of mRNAs in activated $\mathrm{T}$ cells depends on a functional CRM1 nuclear export pathway. J Mol Biol 358: 997-1009.

Segref A, Sharma K, Doye V, Hellwig A, Huber J, Luhrmann R, Hurt E. 1997. Mex67p, a novel factor for nuclear mRNA export, binds to both poly $(\mathrm{A})^{+}$RNA and nuclear pores. EMBO J 16: 32563271.

Shibata S, Matsuoka Y, Yoneda Y. 2002. Nucleocytoplasmic transport of proteins and poly $(\mathrm{A})^{+}$RNA in reconstituted Tpr-less nuclei in living mammalian cells. Genes Cells 7: 421-434.

Smith AJ, Cho MI, Hammarskjöld ML, Rekosh D. 1990. Human immunodeficiency virus type 1 Pr55gag and Pr160gag-pol expressed from a simian virus 40 late replacement vector are efficiently processed and assembled into viruslike particles. $J$ Virol 64: 2743-2750.

Smith AJ, Srinivasakumar N, Hammarskjöld ML, Rekosh D. 1993. Requirements for incorporation of Pr160gag-pol from human immunodeficiency virus type 1 into virus-like particles. J Virol 67: 2266-2275.

Srinivasakumar N, Chazal N, Helga MC, Prasad S, Hammarskjöld ML, Rekosh D. 1997. The effect of viral regulatory protein expression on gene delivery by human immunodeficiency virus type 1 vectors produced in stable packaging cell lines. J Virol 71: 5841-5848.

Swartz JE, Bor YC, Misawa Y, Rekosh D, Hammarskjöld ML. 2007. The shuttling SR protein 9G8 plays a role in translation of unspliced mRNA containing a constitutive transport element. J Biol Chem 282: 19844-19853.

Torrado M, Iglesias R, Nespereira B, Centeno A, Lopez E, Mikhailov AT. 2009. Intron retention generates ANKRD1 splice variants that are co-regulated with the main transcript in normal and failing myocardium. Gene 440: 28-41.

Vaquerizas JM, Suyama R, Kind J, Miura K, Luscombe NM, Akhtar A. 2010. Nuclear pore proteins nup153 and megator define transcriptionally active regions in the Drosophila genome. PLoS Genet 6: e1000846. doi: 10.1371/journal.pgen.1000846. 


\section{Coyle et al.}

Vinciguerra P, Iglesias N, Camblong J, Zenklusen D, Stutz F. 2005. Perinuclear Mlp proteins downregulate gene expression in response to a defect in mRNA export. EMBO J 24: 813-823.

Vomastek T, Iwanicki MP, Burack WR, Tiwari D, Kumar D, Parsons JT, Weber MJ, Nandicoori VK. 2008. Extracellular signal-regulated kinase 2 (ERK2) phosphorylation sites and docking domain on the nuclear pore complex protein Tpr cooperatively regulate ERK2Tpr interaction. Mol Cell Biol 28: 6954-6966.

Walde S, Kehlenbach RH. 2010. The Part and the Whole: functions of nucleoporins in nucleocytoplasmic transport. Trends Cell Biol 20: 461-469.

Wang ET, Sandberg R, Luo S, Khrebtukova I, Zhang L, Mayr C, Kingsmore SF, Schroth GP, Burge CB. 2008. Alternative isoform regulation in human tissue transcriptomes. Nature 456: 470-476.
Wehrly K, Chesebro B. 1997. p24 antigen capture assay for quantification of human immunodeficiency virus using readily available inexpensive reagents. Methods 12: 288-293.

Yoon DW, Lee H, Seol W, DeMaria M, Rosenzweig M, Jung JU. 1997. Tap: A novel cellular protein that interacts with tip of herpesvirus saimiri and induces lymphocyte aggregation. Immunity 6: 571-582.

Zhao J, Hyman L, Moore C. 1999. Formation of mRNA 3' ends in eukaryotes: mechanism, regulation, and interrelationships with other steps in mRNA synthesis. Microbiol Mol Biol Rev 63: 405-445.

Zolotukhin AS, Valentin A, Pavlakis GN, Felber BK. 1994. Continuous propagation of $\operatorname{RRE}(-)$ and $\operatorname{Rev}(-) \operatorname{RRE}(-)$ human immunodeficiency virus type 1 molecular clones containing a cis-acting element of simian retrovirus type 1 in human peripheral blood lymphocytes. J Virol 68: 7944-7952. 

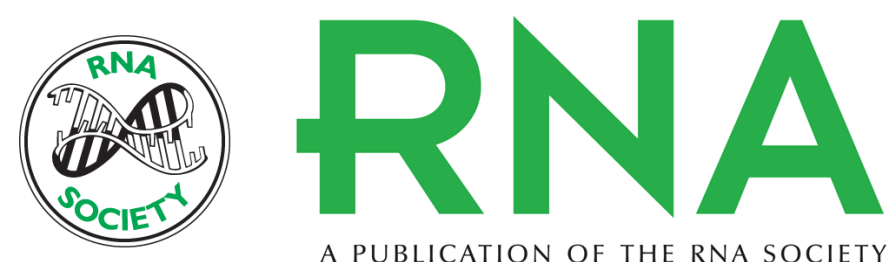

A PUBLICATION OF THE RNA SOCIETY

\section{The Tpr protein regulates export of mRNAs with retained introns that traffic through the Nxf1 pathway}

John H. Coyle, Yeou-Cherng Bor, David Rekosh, et al.

RNA 2011 17: 1344-1356 originally published online May 25, 2011

Access the most recent version at doi:10.1261/rna.2616111

$\begin{array}{ll}\text { References } & \begin{array}{l}\text { This article cites } 63 \text { articles, } 37 \text { of which can be accessed free at: } \\ \text { http://rnajournal.cshlp.org/content/17/7/1344.full.html\#ref-list-1 }\end{array}\end{array}$

License

Email Alerting Receive free email alerts when new articles cite this article - sign up in the box at the Service top right corner of the article or click here.

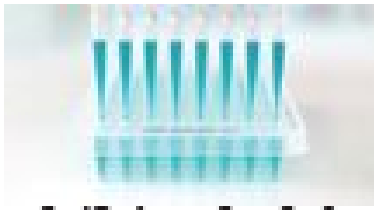

Providing Precise Solutions for your research.

To subscribe to RNA go to:

http://rnajournal.cshlp.org/subscriptions 